\title{
FATORES FACILITADORES E IMPEDITIVOS NO CUIDAR DE SI PARA DOCENTES DE ENFERMAGEM
}

\author{
Raquel Juliana de Oliveira Soares ${ }^{1}$, Regina Célia Gollner Zeitoune², Márcia Tereza Luz Lisboa³, Maria Yvone \\ Chaves Mauro ${ }^{4}$
}

\begin{abstract}
${ }^{1}$ Mestre em Enfermagem. Professora da Universidade Estácio de Sá. Rio de Janeiro, Brasil. E-mail: raquel.jos@superig.com.br
${ }^{2}$ Doutora em Enfermagem. Professora Associado do Departamento de Enfermagem de Saúde Pública (DESP) da Escola de Enfermagem Anna Nery (EEAN), da Universidade Federal do Rio de Janeiro (UFRJ). Rio de Janeiro Brasil. E-mail: regina. zeitoune@gmail.com

${ }_{3}^{3}$ Doutora em Enfermagem. Professora Associado do DEF/EEAN/UFRJ. Rio de Janeiro, Brasil. E-mail: marcialis@terra.com.br

${ }^{4}$ Doutora em Enfermagem. Professora Visitante da Faculdade de Enfermagem da Universidade Estadual do Rio de Janeiro. Rio de Janeiro, Brasil. E-mail: mycmauro@uol.com.br
\end{abstract}

RESUMO: O estudo teve como objetivos descrever os fatores facilitadores e os impeditivos para o cuidar de si do docente de enfermagem e discutir implicações na perspectiva da saúde do trabalhador. Estudo exploratório, tendo como sujeitos 33 professores de três escolas de enfermagem das Universidades Federais do Estado do Rio de Janeiro. Os fatores facilitadores estavam relacionados à consciência em se cuidar, à remuneração, ao relacionamento pessoal e à criatividade. Os impeditivos foram a remuneração, a organização do trabalho, o excesso de atividades, a falta de tempo e a baixa autoestima. Os fatores impeditivos se sobrepõe aos facilitadores para o cuidar de si se caracterizando como obstáculos para as práticas do cuidar de si, gerando desmotivação e prejuízos para a saúde do docente e para a instituição, podendo, inclusive, o mesmo, invadir seu tempo livre, implicando em menos tempo para o lazer, o descanso, o convívio com família e amigos.

DESCRITORES: Enfermagem. Docentes de enfermagem. Saúde do trabalhador.

\section{FACILITATING AND IMPEDING FACTORS TO SELF-CARE AMONG NURSING STUDENTS}

\begin{abstract}
The objectives of this study were to describe the facilitating and impeding factors towards self-care among nursing students and to discuss implications for the worker's health perspective. This exploratory study included 33 teachers from three Brazilian Nursing Schools in Federal Universities in the states of Rio de Janeiro as subjects. The facilitating factors were related to consciousness towards self-care, remuneration, the personal relationship, and creativity. The impeding factors were remuneration, work organization, excess activities, a lack of time, and low self-esteem. The impeding factors overwhelm the facilitating factors to self-care, characterizing themselves as obstacles to self-care practices, generating demotivation and prejudices to the student's health and the institution, thus making it possible to cut into one's free time and implying less leisure time, rest, and spending time with family and friends.
\end{abstract}

DESCRIPTORS: Nursing. Faculty, nursing. Occupational health.

\section{FATORES FACILITADORES Y IMPEDITIVOS EN EL CUIDAR DE SI PARA DOCENTES DE ENFERMERÍA}

RESUMEN: El estudio tuvo como objetivos describir los factores facilitadores y los impeditivos para el cuidar de si del docente de enfermería y discutir implicaciones en la perspectiva de la salud del trabajador. Estudio exploratorio teniendo como sujetos 33 profesores de tres Escuelas de Enfermería de las Universidades Federales del Estado del Rio de Janeiro. Los factores facilitadores estaban relacionados a la consciencia en se cuidar, a la remuneración, al relacionamiento personal y creatividad. Los impeditivos fueron la remuneración, organización del trabajo, exceso de actividades, falta de tiempo y baja auto-estima. Los factores impeditivos se sobreponen a los facilitadores para el cuidar de si caracterizando se como obstáculos para las prácticas del cuidar de si, generando desmotivación y prejuicios para la salud del docente y para la institución, pudiendo inclusive el mismo invadir su tempo libre, implicando en menos tempo para el recreación, el descanso, la convivencia con familia y amigos.

DESCRIPTORES: Enfermería. Docentes de enfermería. Salud laboral. 


\section{INTRODUÇÃO}

$\mathrm{O}$ cuidar de si vem sendo discutido como uma vertente do cuidado. Estudos sobre este tema têm sido desenvolvidos com o intuito de levar o profissional de enfermagem a reflexões acerca da importância do cuidar de si..$^{1-5} \mathrm{O}$ eixo norteador da assistência de enfermagem é o cuidado e, para tanto, existe a real necessidade do investimento no desenvolvimento profissional do enfermeiro, estimulando-o à prática do cuidar de si, não só para proporcionar ao outro um cuidado mais consciente e seguro, mas também para proporcionar a si um nível satisfatório de bem-estar ao que tange a sua saúde enquanto trabalhador.

Com vistas a estas questões, o profissional que pretende cuidar dos outros, antes de tudo, necessita demonstrar que sabe cuidar de si próprio, que conhece os limites do seu fazer, que respeita o outro como um ser diferente de si. ${ }^{4}$

O enfermeiro, sendo o profissional preparado para o cuidado, sempre teve o foco da sua assistência mais voltado para o cuidado do outro, quase nunca o cuidado do cuidador. Na condição de ser humano, o enfermeiro necessita de cuidados e de se cuidar. Enquanto professores, devem estimular o cuidado de si na graduação, colocando-o em prática, para que os futuros enfermeiros e/ou professores de enfermagem tenham a consciência de que também são profissionais e precisam ser cuidados, necessitam olhar para si e cuidar de si. ${ }^{5}$

No ambiente de cuidado, docentes de enfermagem demonstrariam cuidados através não só de conteúdos, mas, também, através de atitudes e comportamentos e na forma como interagem com os alunos. Estes identificam nos professores seus comportamentos de cuidar e passam a introjetá-los. Portanto, se faz necessário que o professor tenha uma postura cuidadosa com relação a si. ${ }^{4}$

Apesar dos estudos sobre a capacidade das pessoas em refletir e fazer coisas benéficas para si, e sobre a importância do cuidar de si, para os professores, essa prática se torna um obstáculo, pois as inúmeras atribuições exigidas hoje pelo mercado de trabalho, somadas às condições ambientais desse trabalho, requerem muito além de um conjunto de conhecimentos técnico-científicos. Neste sentido, a Qualidade de Vida no Trabalho (QVT) do docente de enfermagem é expressa por diversos problemas de saúde que permitem evidenciar que os fatores desgastantes (remuneração, demanda de trabalho, falta de incentivo, dificuldade em participar de congressos, entre outros) se sobrepõem aos fatores potencializados (relação emocionalmente afetiva com alunos, colegas e funcionários, o prazer em ensinar, crescimento dos alunos, entre outros). ${ }^{6}$

"O sofrimento no trabalho, compromete a qualidade do ensino que é desenvolvido com os educandos, e principalmente, causa desgaste ao profissional na sua atuação pedagógica. Mas em alguns casos, o educador não percebe que está sofrendo com esses conflitos que a instituição o submete, e isso gera insatisfação pessoal e profissional em relação ao seu trabalho" ${ }^{\prime: 50}$

$\mathrm{O}$ ambiente de trabalho ao qual alguns professores são submetidos, além de gerar insatisfações, não estimula o professor a cuidar de si. Nesta perspectiva, talvez não falte iniciativa dos professores em cuidar de si, o que falta é tempo e condições favoráveis para fazê-lo. Os professores entendem o que é uma vida melhor, mas devido às condições de trabalho não conseguem colocar em prática. ${ }^{8}$

Essas situações levam a refletir sobre de que forma os fatores internos (da própria pessoa) e os externos (ambientais) contribuem para o cuidar dos professores. Com vistas a estas questões, foram traçados os objetivos: descrever os fatores facilitadores e os impeditivos para o cuidar de si do docente de enfermagem e discutir as implicações destes fatores na perspectiva da saúde do trabalhador.

O estudo justifica-se, do ponto de vista da saúde do trabalhador, pela problemática existente no contexto de trabalho desse docente, no qual existe um ritmo acelerado com diferentes demandas, exigindo deste profissional uma carga de trabalho extensa com muitas horas seguidas de trabalho intelectual e físico, tanto nos cenários de prática, quanto nas salas de aula, atendendo às demandas das atividades de ensino, pesquisa e extensão.

A relevância deste estudo está na discussão sobre a necessidade de investir na saúde do trabalhador docente de enfermagem a partir do que foi possível obter quanto aos fatores facilitadores e impeditivos no que se refere ao cuidar de si.

\section{REFERENCIAL TEÓRICO}

O cuidado, sendo a essência da profissão Enfermagem, a base do ensino e da prática profissional, vem sendo estudado com o intuito de fortalecer a construção do saber da profissão enquanto ciência em plena evolução e "resgatar a história 
da profissão ao trazer à tona os elementos constituintes de uma prática cujas raízes estão fincadas na evolução da humanidade, na sobrevivência e nas relações entre indivíduo e natureza". ${ }^{9: 23} \mathrm{~A}$ enfermagem nasceu das necessidades humanas em relação aos cuidados de saúde. ${ }^{9}$ Este, pode ser visto sobre várias vertentes: cuidado com os animais, natureza, ambiente, objeto, lugar ou com pessoas. E todo cuidado representa envolvimento.

$\mathrm{Na}$ enfermagem, grande parte do avanço teórico, do conceito de cuidado, mostra as influências dos saberes de filósofos, teólogos, psicólogos, estudiosos de enfermagem e de outras áreas do conhecimento. Nesta perspectiva, várias concepções de cuidado têm coexistido e influenciado a prática da enfermagem na atualidade, variando conforme perspectivas teórico-filosóficas e o cenário da prática. Essa coexistência determina práticas, técnicas e formas de intervenção. Neste sentido, uma das teorias de enfermagem mais influentes na enfermagem brasileira é a teoria do autocuidado de Orem. ${ }^{2}$ Porém, mais recentemente, outra perspectiva tem surgido no discurso da enfermagem brasileira, a do cuidado de si mesmo, de Michel Foucault. ${ }^{2}$

Assim, quem cuida de si adequadamente encontra-se em condições de conduzir-se na relação com o outro. O cuidado de si requer um controle e uma delimitação do poder, pois quem cuida de si, conhece a si, e conhece também quais são seus deveres e limites nas diferentes relações que desenvolve. Cuidar de si não é simplesmente uma obrigação; é uma maneira de viver, da qual cada um deve se incumbir ao longo de sua vida. $\mathrm{O}$ cuidado de si nasce como um conjunto de práticas políticas e tem como propósito também produzir acontecimentos políticos. ${ }^{2}$

O conceito de cuidado de si, embora apareça muito menos nos trabalhos acadêmicos da área da saúde, vem sendo utilizado para compreender o sujeito e as relações que estabelecem com os outros, a partir do eixo poder-saber-verdade. ${ }^{2}$

"O cuidar de si inclui o conhecimento de si, que favorece uma melhor autoestima, confiança em si e na vida. Compreende também o cuidar da saúde, do espírito, do intelecto, de seu tempo, do lazer e assim por diante" . 5:132 Assim, existem fatores que facilitam cuidado de si, como o conhecimento, sinceridade, confiança, humildade, esperança, coragem, paciência, aceitação dos ritmos próprios de cada pessoa. ${ }^{5}$ Os fatores facilitadores são estratégias identificadas a fim de tornarem mais fácil o cuidar de si.
Portanto, é preciso que o profissional de enfermagem, hoje, saiba lidar com maestria equilibradamente com a razão e a emoção, que tenha conhecimentos, habilidades e atitudes relacionais, que desenvolva competência interpessoal e capacidade de liderança, que valorize enfim, o seu desenvolvimento como pessoa para balizar o seu desenvolvimento pessoal, visando buscar o desenvolvimento no cotidiano do seu viver, hábitos compatíveis com a sua competência e habilidade profissional, no sentido de promover sua qualidade de vida. ${ }^{10}$

\section{MÉTODO}

O estudo foi exploratório, descritivo, de natureza qualitativa. Teve como local de investigação três escolas de enfermagem de três universidades federais, situadas no Estado do Rio de Janeiro. As mesmas possuem regimes contratuais semelhantes sob o mesmo regime jurídico único.

Os sujeitos do estudo foram 33 professores das escolas de enfermagem, em pleno exercício da profissão, que atuavam na graduação, pós-graduação Lato ou Stricto Sensu, pesquisa, extensão, com cargo administrativo, concomitantemente ou não, escolhidos utilizando a técnica "bola de neve", ou seja, foram convidados para participarem do estudo, por indicação de outro professor. Após o aceite assinaram o Termo de Consentimento Livre e Esclarecido, de acordo com a Resolução 196/96. ${ }^{11}$ Foi explicada a finalidade, os objetivos e a relevância do estudo, ressaltando a importância da participação dos sujeitos.

Utilizou-se como critérios de exclusão os professores afastados para qualificação (Mestrado, Doutorado e Pós-Doutorado), ou por motivo de licença (médica/ especial/ prêmio).

Os sujeitos foram identificados numericamente, de acordo com as universidades (U1.1; U1.2 - U2.1; U2.2 - U3.1; U3.2), conforme a ordem de coleta de dados, e esta se deu no período de janeiro a maio de 2008.

A técnica de coleta de dados utilizada foi a entrevista semiestruturada, tendo como instrumento um roteiro com questões para obter informações dos fatores que facilitam e dos que dificultam o cuidar de si e dados para caracterização dos sujeitos.

Os dados foram coletados nos respectivos locais de trabalho dos sujeitos do estudo e após a transcrição, foram submetidos à análise temática, aproximando os achados em categorias. ${ }^{12} \mathrm{~A}$ dis- 
cussão se deu à luz do referencial teórico eleito para o estudo, sendo ampliado com referenciais bibliográficos, considerando-se os resultados encontrados. Desta forma, emergiram categorias analíticas que foram analisadas à luz da concepção de autores que discutem o cuidado/cuidar/cuidar de si e a saúde do trabalhador.

A etapa de coleta de dados foi iniciada após a aprovação por Comitê de Ética em Pesquisa, da Escola de Enfermagem Anna Nery/Hospital Escola São Francisco de Assis/UFRJ, sob o Protocolo $n^{\circ} 113 / 07$, e mediante a autorização das Escolas, locais de estudo.

\section{RESULTADOS}

Os resultados estão estruturados de acordo com as categorias temáticas emergentes das falas dos sujeitos do estudo, que respondem aos objetivos do estudo, e são elas: Fatores facilitadores para o cuidar de si; Fatores impeditivos para o cuidar de si; e Implicações para a saúde do trabalhador.

\section{Fatores facilitadores para o cuidar de si}

O verbo facilitar significa tornar fácil, pôr à disposição ou ao alcance. ${ }^{13}$ Trazendo estes significados para este estudo, os fatores facilitadores são estratégias identificadas pelos sujeitos, a fim de tornarem mais fácil o cuidar de si. Estes fatores estão relacionados tanto a situações mais concretas (dinheiro, academias, salão de beleza, entre outros), como estão também relacionados a situações subjetivas (vontades, consciência, conhecimento, relacionamento interpessoal, entre outros).

Alguns fatores podem facilitar o cuidado de si, como o conhecimento, a sinceridade, a confiança, a humildade, a esperança, a coragem, a paciência e a aceitação dos ritmos próprios de cada pessoa. ${ }^{12} \mathrm{Nesta}$ perspectiva, tem-se as falas de professores que vêem na sua disposição interna, fatores que facilitam seus cuidados.

Facilitador, eu acho que é só a vontade de você cuidar de você, né. É a vontade de não deixar a rotina te consumir, porque se você deixar, é consumido e você fica para último plano. Acho que isso é facilitador (U2.5).

Outro facilitador também é a consciência de que eu preciso me cuidar (U2.4).

Facilitador eu acho que é eu gostar de viver (U1.3).

Esses relatos vão ao encontro do que autores destacam como importante para se cuidar: aquele que pretende cuidar dos outros e dirigi-los, antes de tudo, necessita demonstrar que sabe dirigir a si próprio, que conhece os limites do seu fazer. ${ }^{4}$

Para alguns professores, o fator remuneração aparece como facilitador.

Os facilitadores são você ter remuneração adequada, ter uma verba para você gastar, lógico, se você não tem verba para gastar é um fator impeditivo, a remuneração (U1.1).

Um fator facilitador é a gente ter um certo equilíbrio financeiro para você poder se cuidar, ter um plano de saúde que você tenha um certo acesso (U3.4).

De certa forma, o fator remuneração pode aparecer nas entrelinhas dos outros relatos como positivo, a partir do momento em que se colocam as facilidades, como morar perto do trabalho, perto de áreas de lazer, locais para exercícios e pagar plano de saúde. Porém, só é caracterizado como positivo, se as pessoas tiverem essa consciência.

[...] moro próximo do meu trabalho... perco pouco tempo me deslocando, e isso sobra mais tempo para fazer atividade física, uma atividade de lazer, mesmo depois do trabalho (U2.3).

Eu tenho área de lazer para fazer esporte, por exemplo. Tem academias perto da minha casa (U2.6).

Eu estabelecer um tipo de moradia que não me obrigue estar limpando, lavando casa e nem cuidando de cachorro, nem nada, é um fator facilitador (U3.9).

Outro fator facilitador, para o cuidado de si dos professores, e muito importante, é o relacionamento interpessoal. Os convívios sociais que permitem o estabelecimento de vínculos de amizade com o grupo de trabalho são muito valorizados. A valorização do trabalho é determinada pelas relações interpessoais estabelecidas com os colegas e pela segurança proporcionada quanto à satisfação das necessidades materiais. ${ }^{14}$

O facilitador, eu acho que ele vem das relações de amizade que a gente tem, né? Porque muitas vezes nossos amigos, nossos colegas, chamam a nossa atenção para algumas questões, procuram nos ajudar, a gente procura se ajudar nisso (U1.2).

Assim, resultados atestaram que o relacionamento profissional que conduz ao desenvolvimento do pensamento reflexivo, o prazer de criar e recriar coisas e, também, a valorização de si mesmo pelos outros, são condições potencializadoras desta QVT. ${ }^{8}$

Perceber de forma acurada uma situação e suas variáveis, permite que o sujeito desempenhe melhor o seu trabalho, tanto na dimensão técnica requerida pela natureza dessa atividade quanto na 
de ser capaz de se posicionar de forma habilidosa na rede de relações interpessoais, interna e externa, no local de trabalho.

Ter conhecimento. Enquanto enfermeiro, professor de enfermagem, professor de saúde pública, esse é um fator facilitador. É ter acesso à boa alimentação. Eu tenho, eu tenho boa alimentação, lazer, é facilitador de cuidar de si (U1.7).

Bom, os facilitadores em relação à educação que tive dos meus pais, eles sempre priorizaram muito a higiene, a alimentação, ter um lugar sossegado, respeitar as pessoas, valorizar o relacionamento humano, o trabalho, os vizinhos [...] (U3.6).

Pode-se perceber que o conhecimento e a bagagem da formação são fatores importantes para o próprio cuidado. Importante para o desenvolvimento do próprio cuidado é ter consciência do que faz bem e o que faz mal, e a liberdade de optar pelo fator que mais agrada. ${ }^{4}$

Acho que é o estilo de vida. Vir para trabalhar de dia, para mim, foi um agente facilitador, no meu caso em particular. Facilitador, eu moro perto do meu trabalho, né? (U2.3).

O meu modo de ver as coisas mesmo, facilita para poder dar a criatividade, eu sou uma pessoa criativa, pois às vezes, com pouco dinheiro, eu consigo cuidar esteticamente e também, lógico, se eu vou cuidar do meu corpo, eu cuido da minha alimentação (U3.10).

Morar próximo ao trabalho, sem ter que perder horas no trajeto, é um fator que facilita a vida dos trabalhadores, pois, além da perda de tempo, a retenção no trânsito provoca ainda o aumento do custo de operação de cada veículo, combustível e o desgaste de peças. Por isso, morar próximo do trabalho é um fator que facilita, tanto por conta do tempo, quanto por conta dos prejuízos financeiros que podem ser evitados, ${ }^{15}$ corroborando com a fala dos sujeitos do estudo.

Outro fator de destaque é a criatividade. $\mathrm{O}$ professor é um elemento fundamental para incentivar o desenvolvimento da criatividade em seus alunos, porém, como despertar a criatividade nos alunos, sem se utilizar da sua própria criatividade? Há relato que os professores mostram, exatamente, que há a necessidade de ser criativo para o desenvolvimento das suas práticas de cuidar, e julga ser esse o seu fator facilitador. ${ }^{16}$ A criatividade possibilita ao ser humano a participação ativa no processo de transformar a realidade, assegurando-lhe que sua singularidade pode se manifestar, no coletivo do qual faz parte, através de suas ações, de suas reflexões. ${ }^{16}$
Como fatores externos, que podem agir como facilitadores ou inibidores do processo criativo, têm-se, como exemplos, a sociedade com suas normas e convenções, o processo político, a família, a escola, o ambiente de trabalho e outros grupos dos quais o indivíduo faz parte.

Praticamente nenhum fator, porque hoje tudo é muito difícil, foi o que te falei, se você tiver um SUS plus, ótimo, se você não tiver, vocêtem que ter um plano de saúde (U3.8).

Acho que tem poucas coisas que me facilitam fazer as coisas. Tive que aprender a criar tempo. Eu aprendi a criar tempo para mim, e isso, para mim, é um fator facilitador (U2.7).

Há também que se destacar que, para alguns professores, quase não há fatores facilitadores para seu cuidar de si. Isso mostra como é difícil desenvolver uma ação de cuidado para si, favorecendo, assim, um ambiente que possa proporcionar o desenvolvimento de doenças físicas e psíquicas. ${ }^{17}$

\section{Fatores impeditivos para o cuidar de si}

Os professores do curso de graduação de universidades públicas federais sofrem constantemente com a grande demanda de trabalho e as condições de trabalho atuais. Horário de trabalho, remuneração, burocracia, submissão, impotência, competitividade, cobrança, incompatibilidade entre afazeres, a família e o lazer, são fatores que afetam a sua saúde. ${ }^{17}$

Nesta categoria, pode-se perceber que os fatores mais apontados pelos professores, como aqueles que dificultam o próprio cuidado, foram: demanda de trabalho, organização do trabalho e tempo. Estes fatores se inter-relacionam, na medida em que um depende do outro, para a execução do trabalho.

A nossa organização de trabalho é um fator impeditivo (U1.2).

Uma situação que dificulta, no meu caso, na minha atividade laborativa, na minha vida, é o trabalho do professor, que é inevitável levar trabalho para casa. Então, um agente dificultador é isso, o fato de levar trabalho para casa, muitas vezes (U2.3).

A organização do trabalho deve ser vista antes que qualquer coisa, como uma relação socialmente construída e não somente em sua dimensão estritamente tecnológica, cognitiva ou física. ${ }^{7} \mathrm{Nes}-$ ta perspectiva, a organização do trabalho aparece, antes de tudo, como uma relação intersubjetiva e uma relação social e isto, exige sempre, reajustes 
e reinterpretações pelos atores sociais. A intersubjetividade também aparece no próprio centro das organizações do trabalho, e esta é, definitivamente determinada pelas relações sociais de trabalho. ${ }^{7}$

De acordo com os relatos, o fator demanda de trabalho gera uma dificuldade para o cuidado que os professores destinam a si, colocando-os mais vulneráveis ao cansaço, estresse e desenvolvimento de doenças.

Impeditivos, que é mais fácil de falar: excesso de atividades; eu tenho a clareza que eu tenho excesso de atividades [dois empregos], e isso, para mim, é um fator impeditivo (U3.5).

Agora, fatores impeditivos, são, na realidade, os de trabalho. Se você tem que dar conta de um projeto, tem uma tese para ler, ninguém consegue fazer um exercício, e está, ao mesmo tempo, fazendo uma produção intelectual de alta concentração (U3.9).

O estudo conclui que quanto maior o número de horas semanais trabalhadas, menores são os níveis de saúde dos professores. Esses resultados são preocupantes, uma vez que professores são trabalhadores e merecem ter seus momentos adequados de descanso e de lazer. Importante destacar que os professores que têm uma grande demanda de trabalho, acabam, como já foi relatado anteriormente, ultrapassando suas $40 \mathrm{~h}$ de trabalho, pelas quais foram contratados. ${ }^{18}$

Associado ao fator demanda de trabalho, o fator falta de tempo, também foi destacado como um grande contribuinte para dificultar os cuidados dos professores.

Falta de tempo. Tem momentos em que 24 horas é pouco para você realizar tudo o que tem que realizar, então é claro e evidente que você vai fazer o que é prioritário, e vai deixar de mão aquilo que você acha que é importante para você (U2.1).

Seria o tempo, hoje em dia, pelo menos nesses últimos três anos, o tempo pra mim tem sido muito escasso (U2.4).

Foi possível encontrar falas em que a realidade de quem, mesmo tendo fatores que facilitam o seu cuidado, não faz uso constante desses fatores, pois o tempo não permite.

[...] dificultadores [...] não tenho tempo, tenho as facilidades, mas não tenho tempo (U2.6).

Eu acho que o que dificulta muito é que a gente não tem os horários fixos. Quando eu estou em atividade, no campo de estágio, acho que fica extremamente complicado... não tem os horários muito certos para fazer as coisas (U2.7).
Outro aspecto muito destacado entre os professores entrevistados foi o dinheiro (a falta dele), sendo este, apontado como fator que dificulta seus cuidados, uma vez que a remuneração, para muitos, não é compatível com a demanda de trabalho.

A questão do (des) respeito aos trabalhadores, as condições da mulher e suas jornadas de trabalho, e a dificuldade do próprio sistema de saúde, foram também colocados pelos sujeitos do estudo.

Dificultador é você conseguir marcar uma consulta, é você conseguir fazer um exame que você esteja precisando, e que precisa de uma urgência na entrega do resultado, eu acho que basicamente... então, outro fator que dificulta, você vai perdendo o poder aquisitivo e os planos de saúde vão ficando mais caros. Então é um outro fator (U3.8).

Há o paradoxo de desenvolver programas de saúde para os outros, sendo que eles mesmos não participam, e também a incoerência de estar dentro das instituições de saúde (com alunos, com projetos de extensão, sendo funcionário da universidade) e não poder usufruir (até mesmo pela dificuldade de marcar um atendimento) dos serviços que os hospitais universitários disponibilizam para a comunidade.

Então, o próprio atendimento [...], vocêprecisa, e com muita dificuldade você é atendido no próprio hospital que você trabalha. A gente cria um programa de hipertensão pro aluno atuar, mas não para os professores hipertensos (U3.8).

Cabe aqui destacar a fala de um entrevistado, referente ao tratamento dado aos trabalhadores, caracterizando um fator que dificulta seu cuidado:

[...] é a discriminação, o preconceito, o desrespeito ao trabalho, desrespeito ao trabalhador (U3.6).

[...] a gente não se respeita e nem o outro respeita os horários que a gente tem, acho que uma coisa que dificulta muito é isso (U2.7).

Desta feita, a desvalorização do professor, aliada às condições de trabalho, se caracterizam como fatores que impedem o desenvolvimento de práticas do próprio cuidado.

Deve-se ressaltar que alguns professores não vêem a demanda de trabalho como um fator dificultador. Para eles, é importante saber planejar e reconhecer seus limites, sabendo dizer não quando necessário. Porém, apesar desses relatos, a maioria dos professores entrevistados ainda sofre com essa organização de trabalho atual dentro das universidades federais onde foi realizada a pesquisa.

Outro fator que chamou a atenção, e que 
somente uma entrevistada colocou, é a questão da baixa autoestima.

Agora, fator complicador é a baixa autoestima, e muito trabalho (U1.7).

Professores e alunos com baixa autoestima, são pessoas infelizes, incapazes de considerarem a si mesmos como membros aceitáveis, criaturas significativas. Por outro lado, a baixa autoestima pode estar associada às condições de trabalho. ${ }^{4,8}$

Neste contexto, os professores podem estar desenvolvendo a Síndrome de Burnout, ${ }^{19}$ que é um fenômeno psicossocial que surge como uma resposta crônica aos estressores interpessoais ocorridos na situação de trabalho, que acomete profissionais que mantêm uma relação constante e direta com outras pessoas, como professores, médicos, enfermeiros, psicólogos, entre outros.

A baixa autoestima, associada a outros sintomas, como impaciência, distanciamento afetivo, sentimento de solidão, sentimento de alienação, irritabilidade, ansiedade, dificuldade de concentração e sentimentos de impotência, são considerados consequências do burnout. ${ }^{20}$

\section{Implicações para a saúde do trabalhador}

Ao analisar os fatores facilitadores e impeditivos para o cuidar de si e de que forma estes fatores estão contribuindo para a prática do cuidar de si pelos professores, percebe-se que, apesar de conhecerem fatores facilitadores, e terem acesso a eles, estes não são suficientes para levaram os sujeitos a por em prática, periodicamente, os cuidados com relação a si.

Com relação aos fatores impeditivos para o cuidar de si, foi percebido que estes fatores geraram uma atitude desfavorável devido às circunstâncias nas quais este cuidar de si está inserido: organização do trabalho, demanda de trabalho, falta de tempo, dificuldade em agendar atendimento médico, falta de dinheiro, entre outros.

Nesta perspectiva, a saúde deste profissional fica prejudicada, na medida em que se o professor não consegue por em prática o cuidar de si, devido a fatores impeditivos, se está cansado, estressado, desanimado, certamente esse comportamento o acompanhará também dentro do seu ambiente de trabalho. Cabe então resgatar que o homem é um ser biopsicossocial, um todo integrado e organizado que se inter-relaciona constantemente. ${ }^{5}$

Portanto, vale reflexão a respeito da falta de apoios estruturantes (da instituição), no sentido de favorecer a este professor, circunstâncias mais facilitadoras que impeditivas para o cuidar de si.

\section{CONSIDERAÇÕES FINAIS}

A realização deste estudo proporcionou a reflexão acerca dos fatores que facilitam ou dificultam os professores para cuidarem de si. Os resultados mostram que os fatores impeditivos acabam, de certa forma, sobrepondo-se aos fatores facilitadores para o cuidar de si, e que os fatores impeditivos, na maioria das vezes, estão relacionados ao trabalho (organização do trabalho, demanda de trabalho), apesar de terem sido relatados pela minoria. Vale destacar que, para alguns professores, os fatores impeditivos estão relacionados à falta de acesso a serviços de saúde e a remuneração.

Com este comportamento constante, percebe-se que os professores tendem ao adoecimento e que isso certamente afetará sua vida laboral. Portanto, ter este comportamento de não cuidar de si ou de ter um cuidado mínimo consigo favorece ao prejuízo com relação à saúde na condição de trabalhador.

Desta forma, estes trabalhadores terão dificuldades em desenvolver suas atividades com a devida atenção, ficando desmotivados facilmente, bem como emocionalmente mais abalados e também ficarão assim em seu ambiente doméstico.

Neste sentido, as instituições, local de trabalho dos professores, devem repensar a organização do trabalho e as condições impostas a estes professores, uma vez que se o profissional não tem boas condições de trabalho e tem uma demanda grande de trabalho, não consegue ter tempo para atender suas necessidades, bem como ter um tempo para o cuidar de si. O prejuízo não é somente para o trabalhador, mas também para as instituições, pois a tendência é o aumento das licenças por motivo de doença o que levará a uma sobrecarga dos outros professores e colocando estes também em risco, uma vez que a demanda de trabalho aumentará tornando uma problemática e um ciclo vicioso.

\section{REFERÊNCIAS}

1. Foucault M. História da sexualidade 3: o cuidado de si. Rio de Janeiro (RJ): Graal; 1985.

2. Bub MBC, Medrano C, Silva CD, Wink S, Santos EKA. A noção de cuidado de si mesmo e o conceito de autocuidado na enfermagem. Texto Contexto Enferm. 2006; 15(Esp):152-57.

3. Oliniski SR, Lacerda MR. Cuidando do cuidado no ambiente de trabalho: uma proposta de ação. 
Rev Bras Enferm. 2006 [acesso 2011 Set 28]; 59(1):100-4. Disponível em: http://www.scielo. br/scielo.php?script=sci_arttext\&pid=S003471672006000100019\&lng=en

4. Santos VEP, Radünz, V. O cuidar de si na visão de acadêmicas de enfermagem. Rev Enferm UERJ. 2011 Jan-Mar; 19(1):46-51.

5. Waldow VR. O cuidado na saúde: as relações entre o eu, o outro e o cosmos. Petrópolis (RJ): Vozes; 2004.

6. Rocha VM, Fernandes MH. Qualidade de vida de professores do ensino fundamental: uma perspectiva para a promoção da saúde do trabalhador. J Bras Psiquiatr [online]. 2008 [acesso 2011 Set 28]; 57(1):23-7. Disponível em: http://www.scielo. $\mathrm{br} /$ scielo.php?script=sci_arttext\&pid=S004720852008000100005\&lng=en

7. Vasconcelos CMCB, Prado ML. Vivendo o sofrimento e os desafios no trabalho: expressões autocríticas de um grupo de enfermeiros-educadores. Rev Eletr Enferm [online]. 2004 [acesso 2007 Mai 25]; 6(1). Disponível em: http://www.fen.ufg.br/revista/ revista6_1/pdf/f5_desafios.pdf

8. Webler RM, Ristow, MR. O mal-estar e os riscos da profissão docente. Ciênc Sociais Aplic Rev [online]. 2006 [acesso 2007 Jun 29]; 6(11). Disponível em: http:/ / e-revista.unioeste.br/index.php/ csaemrevista/issue/current

9. Espírito Santo FH, Porto IS. Cuidado de enfermagem: saberes e fazeres de enfermeiras novatas e veteranas no cenário hospitalar. Rio de Janeiro (RJ): UFRJ/ EEAN; 2006.

10. Santos I, Cavalcante LB, Berardinelli LMM. Estudos sobre hábitos de vida de docentes de enfermagem segundo modos adaptativos de Roy. Rev Enferm UERJ. 2010 Jan-Mar; 18(1):48-54.

11. Ministério da Saúde (BR), Conselho Nacional de Saúde, Comissão Nacional de Ética em Pesquisa. Resolução No 196 de 10 de outubro de 1996: diretrizes e normas regulamentadoras de pesquisa envolvendo seres humanos. Brasília (DF): MS; 1996.

12. Bardin L. Análise de conteúdo. Lisboa (PT): Edições 70; 1995.

13. Ferreira ABH. Dicionário da língua portuguesa. São Paulo (SP): Melhoramentos; 2006.

14. Garcia AL, Oliveira ERA, Barros EB. Qualidade de vida de professores do ensino superior da área da saúde: discurso e prática cotidiana. Cogitare Enferm [online]. 2008 [acesso 2011 Set 28]; 13(1):18-24. Disponível em: http://ojs.c3sl.ufpr.br/ojs2/index. $\mathrm{php} /$ cogitare/article/view/11945/8429

15. Marandola Júnior E. Entre muros e rodovias: os riscos do espaço e do lugar. Antropolítica UFF. 2008; 24: 195-218.

16. Rocha KB, Sarriera JC. Saúde percebida em professores universitários: gênero, religião e condições de trabalho. Psicol Esc Educ [online]. 2006 [acesso 2008 Abr 02]; 10(2). Disponível em: http:/ / scielo.bvs-psi.org.br/scielo.php?pid=S1413

17. Dalmolin GL, Lunardi, VL, Lunardi Filho, WD. O sofrimento moral dos profissionais de enfermagem no exercício da profissão. Rev Enferm UERJ. 2009 Jan-Mar; 17(1):35-40.

18. Dias J, Nascimento LC, Mendes IJM, Rocha SMM. Promoção de saúde das famílias de docentes de enfermagem: apoio, rede social e papéis na família. Texto Contexto Enferm. 2007 Out-Dez; 16(4):688-95.

19. Maslach C, Schaufeli WB, Leiter MP. Job burnout. Ann Rev Psychol. 2001 Feb; 52: 397-422.

20. Batista JBV, Carlotto MS, Coutinho AS, Augusto LGS. Prevalência da Síndrome de Burnout e fatores sociodemográficos e laborais em professores de escolas municipais da cidade de João Pessoa, PB. Rev Bras Epidemiol. 2010 [acesso 2011 Set 28]; 13(3):502-12. Disponível em: http:/ / www.scielosp. org / scielo.php?script=sci_arttext\&pid=S1415790X2010000300013\&lng=en 